\title{
O CONTO MARAVILHOSO “A GUARDADORA DE GANSOS”: FUNÇÃO DAS PERSONAGENS, SEGUNDO PROPP
}

\author{
Vanilda Salton Köche*
}

\begin{abstract}
Resumo: O conto maravilhoso é uma das formas de manifestação literária mais importantes na literatura universal; arte criativa que representa o mundo, o homem e a vida, através da palavra. É um gênero textual com o qual o aluno convive desde as séries iniciais e, além disso, é bastante estudado nos Cursos de Letras do país. Este estudo objetiva analisar o conto “A guardadora de gansos”, dos irmãos Grimm, a partir da localização das personagens estabelecidas por Propp, em sua obra “A morfologia do conto” (1970). Nessa análise, foram encontradas treze funções: interdição, afastamento, transgressão, engano, malfeitoria, chegada incógnita, objeto mágico, reparação, reconhecimento, descoberta, transfiguração, punição e casamento. O artigo faz parte da pesquisa-ensino intitulada "O ensino da leitura e escrita a partir dos gêneros textuais", desenvolvida na Universidade de Caxias do Sul - Campus Universitário da Região dos Vinhedos, cujo objetivo é investigar os gêneros textuais e sua aplicação no ensino de leitura e produção textual no Ensino Médio e Superior.
\end{abstract}

Palavras-chave: Conto maravilhoso; a guardadora de gansos; funções; Propp.

\section{Introdução}

O gosto por narrativas nasceu com a humanidade. O contar e o ouvir histórias está relacionado a um desejo inato no ser humano: o de conhecer. Inicialmente, as narrativas se realizavam de forma oral, tendo como espaço de registro apenas a memória. Depois, com o advento da escrita, essas histórias foram registradas no papel.

O conto popular, criado pelo imaginário coletivo, caracteriza-se pelo encantamento, envolvendo situações em que ocorrem transformações, por algum tipo de magia, que não se explicam pela razão. Nesse gênero textual, revela-se a inventividade, através de situações extremas, e toma-se contato com povos, situações e costumes distantes.

Este artigo tem o propósito de analisar o conto maravilhoso intitulado “A guardadora de gansos”, de Grimm, a partir da localização das funções estabelecidas por Propp (1970). A análise é relevante por ser o conto maravilhoso uma das formas de manifestação literária mais importantes na literatura universal; arte criativa que representa o mundo, o homem e a vida, através da palavra. É ainda um gênero textual trabalhado das séries iniciais à Universidade. Fundamentam este trabalho os autores Gotlib (1985); Machado (1994) e Propp (1970).

\footnotetext{
* Mestre em Estudos de Linguagem pela Universidade Federal do Rio Grande do Sul. Professora das disciplina de "Leitura e Produção Textual”, "Língua Portuguesa para Licenciaturas” e "Leitura e escrita na formação Universitária” da Universidade de Caxias do Sul - Campus Universitário da Região dos Vinhedos. Subcoordenadora do Curso de Letras da UCS/CARVI desde 2000. Coordena o Curso de Especialização em Leitura e Produção Textual. É autora do Livro "Prática textual: atividades de leitura e escrita", editado pela Vozes. Coordena a pesquisa intitulada o "O ensino da leitura e produção textual a partir dos gêneros textuais".
} 


\section{O conto maravilhoso}

O conto maravilhoso propaga-se através do tempo, sem perder sua forma básica. No século XVII, Perrault reuniu esses contos em um único volume intitulado "Histórias de Mamãe Gansa". No século XIX, os irmãos Grimm fizeram um trabalho similar.

Para Propp, conto maravilhoso é, do ponto de vista morfológico, o desenrolar de uma ação que parte de uma malfeitoria ou falta e passa por funções intermediárias, acabando em casamento ou em outras funções utilizadas como desfecho (1970: 144).

O espaço em que ocorre a ação no conto maravilhoso é regido por leis sobrenaturais, não existindo distâncias, e as personagens deslocam-se de um espaço a outro com grande facilidade. O tempo não é cronológico. Trata-se de um tempo distante do que vivenciamos. Por isso, inicia geralmente por “Era uma vez”..., "Num tempo distante”..., “Existiu outrora”... Tudo ocorre de repente, sem referência aos antecedentes dos acontecimentos. Nesse espaço e nesse tempo, habitam seres maravilhosos, responsáveis pelas transformações provocadas por algum tipo de magia, no destino das personagens.

\section{As funções das personagens no conto maravilhoso}

Para entender o conto maravilhoso, Propp (1970) determinou uma morfologia do conto, ou seja, ele fez uma descrição, conforme as partes e personagens que o constituem. Encontrou sete tipos de personagens, cada uma com sua esfera de ação. Essas personagens denominam-se: o antagonista ou agressor, o doador, o auxiliar, a princesa e seu pai, o mandatário, o herói e o falso herói. É a partir da análise da ação das personagens, que Propp identifica ações constantes, que denomina funções. $\mathrm{O}$ autor encontrou trinta e uma funções, cuja sucessão é recorrente. Os processos ou passagens de uma função a outra são os movimentos do conto. Analisá-lo, sob o ponto de vista morfológico, significa determinar esses movimentos.

Conforme Machado, função é o papel representado pela personagem no desenrolar da ação. De acordo com as ações e reações das personagens, a história vai evoluindo, acumulando conflitos até chegar à solução (1994: 48). Para Propp, função é a ação de uma personagem, definida do ponto de vista de sua significação no desenrolar da intriga (1970: 31). De acordo com Propp, é de extrema importância o estudo do que fazem as personagens: quem faz e como faz são questões complementares.

Analisando o conto, Propp estabelece quatro princípios:

1. os elementos constantes e permanentes são as funções das personagens, sejam quais sejam essas personagens e qual seja a maneira como essas funções são preenchidas, e as funções são o elemento fundamental do conto;

2. o número de funções presentes é limitado, embora ilimitado seja o número de contos; as 
funções não são todas encontradas num determinado conto, porém, a ausência de uma função não modifica em nada a estrutura do conto: as outras funções conservam o seu lugar.

3. a sucessão das funções é sempre idêntica, repetindo-se nas diferentes obras;

4. todos os contos maravilhosos pertencem ao mesmo tipo, no que concerne a sua estrutura (1970: 134).

\section{Sequência de funções determinadas por Propp}

Situação inicial

I. Um dos membros da família afasta-se de casa (definição: afastamento).

II. Ao herói impõe-se uma interdição (definição: interdição).

III. A interdição é transgredida (definição: transgressão).

IV. O agressor tenta obter informações (definido: interrogação).

V. O agressor recebe informações sobre a sua vítima (definição: informação).

VI. O agressor tenta enganar a sua vítima para se apoderar dela ou dos seus bens (definição: engano).

VII. A vítima deixa-se enganar e ajuda assim o seu inimigo sem o saber (definição: cumplicidade).

VIII. O agressor faz mal a um dos membros da família ou prejudica-o (definição: malfeitora).

VIII-a. Falta qualquer coisa a um dos membros da família; um dos membros da família deseja possuir qualquer coisa (definição: falta).

IX. A notícia da malfeitoria ou da falta é divulgada; dirige-se ao herói um pedido ou uma ordem: este é enviado em expedição ou deixa-se que parta de sua livre vontade (definição: mediação, momento da transição).

X. O herói-que-demanda aceita ou decide agir (definição: início da ação contrária).

XI. O herói deixa a casa (definição: partida).

XII. O herói passa por uma prova, um questionário, um ataque etc., que o preparam para o recebimento de um objeto mágico (definição: primeira função do doador).

XIII. O herói reage às ações do futuro doador (definição: reação do herói).

XIV. O objeto mágico é posto à disposição do herói (definição: recepção do objeto mágico).

XV. O herói é transportado, conduzido ou levado perto do local onde se encontra o objetivo da sua demanda (definição: deslocação no espaço entre dois reinos, viagem com um guia). 
XVI. O herói e seu agressor defrontam-se em combate (definição: combate).

XVII. O herói recebe uma marca (definição: marca).

XVIII. O agressor é vencido (definição: vitória).

XIX. A malfeitoria inicial ou a falta são reparadas (definição: reparação).

XX. O herói volta (definição: volta).

XXI. O herói é perseguido (definição: perseguição).

XXII. O herói é socorrido (definição: socorro).

XXIII. O herói chega incógnito a sua casa ou a outro país (definição: chegada incógnito).

XXIV. Um falso herói faz valer pretensões falsas (definição: pretensões falsas).

XXV. Propõe-se ao herói uma tarefa difícil (definição: tarefa difícil).

XXVI. A tarefa é cumprida (definição: tarefa cumprida).

XXVII. O herói é reconhecido (definição: reconhecimento).

XXVIII. O falso herói ou o agressor, o mau, é desmascarado (definição: descoberta).

XXIX. O herói recebe uma nova aparência (definição: transfiguração).

XXX. O falso herói ou o agressor é punido (definição: punição).

XXXI. O herói casa-se e sobe ao trono (definição: casamento).

\section{A história}

“A guardadora de gansos” narra a história de uma princesa que, ao chegar à idade de casar, teve que viajar para um país estrangeiro, para encontrar seu futuro marido. A mãe deu-lhe joias preciosas e tesouros, designando uma dama de companhia. Cada uma recebeu um cavalo para a viagem, sendo que o da princesa chamava-se Falante, uma vez que podia falar. A mãe deu-lhe também um lenço branco, com três gotas de seu sangue, para a princesa levar consigo, servindo-lhe de proteção.

Durante a viagem, a princesa teve sede e pediu água à dama de companhia. Essa recusou-se a atender seu pedido e disse que não seria mais sua criada. Mais tarde, repetiu-se a cena, e quando a princesa debruçou-se para beber água no rio, deixou cair o lenço dado pela mãe, tornando-se, assim, frágil e sem forças. A criada aproveitou-se do momento e forçou a princesa a trocar os cavalos e as roupas, fazendo-a jurar, sob ameaça de morte, que não contaria nada para ninguém da corte real. 
Na chegada, tomaram a criada pela noiva. A verdadeira princesa foi designada para ajudar um menino, guardador de gansos. A falsa princesa pediu a seu noivo que cortasse a cabeça do cavalo falante, temendo que ele revelasse sua ação malvada. Isso feito, a cabeça foi colocada sobre um portão negro, atendendo às súplicas da então guardadora de gansos.

Todas as manhãs, quando a verdadeira princesa e o garoto passavam pelo portão, a cabeça de Falante lamentava a condição da moça. Esse fato causava estranheza ao menino.

Na colina, o garoto e a princesa guardavam os gansos. Certa vez, ao vê-la desmanchar suas tranças douradas, o menino quis arrancar-lhe um punhado de seus cabelos. Ela impediu-o, chamando o vento, que soprou o chapéu dele para longe, obrigando-o a correr atrás. Isso aconteceu por dias consecutivos.

Intrigado, o menino relatou ao rei as estranhas palavras da cabeça falante, dirigidas à moça. Então, o rei escondeu-se atrás do portão, observando tudo, e interrogou a pastora princesa que disse não poder revelar o que estava acontecendo em função de uma promessa, mas aceitou contar tudo à lareira. O velho rei escondeu-se atrás da mesma, conhecendo toda a verdade.

Depois disso, o rei ofereceu roupas reais à verdadeira princesa, e todos foram convidados para uma festa. A verdadeira e a falsa princesa sentaram-se ao lado do jovem rei. No final da refeição, o velho rei perguntou à impostora qual seria a punição para uma pessoa que agisse da forma pela qual ela agira de fato. Não sabendo que havia sido descoberta, ela respondeu que deveria ser condenada a morrer na forca, por ser uma criminosa. Então, o rei decretou-lhe a pena, conforme ela mesma determinara. A aia foi executada, e o jovem rei e a verdadeira princesa casaram-se, vivendo felizes para sempre.

\section{Localização das funções de Propp no conto “A guardadora de gansos”}

Situação inicial

O autor introduz a situação inicial da narrativa, apresentado as personagens: uma rainha viúva, sua filha, uma princesa lindíssima, que estava prometida a um príncipe de um reino muito distante, e uma aia escolhida para acompanhar a filha, a fim de ir ao encontro do noivo.

O tempo é referido como "outrora”, sugerindo uma atemporalidade, um tempo distante e não localizado. O espaço é “trans-real”, isto é, criado pela imaginação do homem, o que se evidencia pelo uso de expressões como "reino muito distante":

Existiu outrora uma rainha viúva, mãe de uma filha lindíssima. A jovem estava prometida a um príncipe de um reino muito distante, e, quando se aproximou a hora do casamento, a viúva, que adorava a filha, preparou-lhe o enxoval com muito carinho, com as mais belas e finas roupas, joias e objetos preciosos de ouro e prata, enfim, tudo o que o enxoval de uma princesa deve ter. E escolheu uma de suas aias para acompanhar a filha e entregá-la nas 
mãos do noivo (GRIMM: 1995: 1).

\section{Interdição reforçada por conselho}

A interdição reforçada por conselho refere-se ao momento em que a mãe foi ao quarto e, com a faquinha, deu um corte no dedo até sangrar, deixando cair três gotinhas de sangue em um lenço, dando-o à filha para servir-lhe de proteção em sua viagem. Esse lenço configura-se como um amuleto com poderes mágicos e, se bem guardado, a protegeria de todos os males: "Filha querida, guarde bem este lenço que há de protegê-la durante toda a viagem” (GRIMM, 1995: 2).

\section{Afastamento da princesa}

O afastamento de uma personagem constitui um dos desencadeadores da ação. A jovem princesa estava prometida a um príncipe. Chegada a época de casar, ela viaja para ir ao encontro do noivo. Nessa viagem, ocorrem os fatos que originam a trama do conto.

E com o coração apertado de tristeza, despediram-se uma da outra. A princesa guardou o lencinho no seio, montou no seu cavalo, que se chamava Falante, porque sabia falar, e, acompanhada da aia, partiu ao encontro do noivo (GRIMM, 1995: 2).

\section{Transgressão da interdição}

A transgressão consiste no não atendimento ao conselho recebido pela mãe. A princesa perde o lenço que a protegeria de todos os males, tornando-se frágil e vítima da malfeitoria da criada que resolve não mais obedecê-la:

Aconteceu que, por ter se inclinado muito para beber, o lencinho com as gotas de sangue escapou de seu decote, caiu n'água e foi levado pela correnteza. Ela nem deu por isto tão angustiada estava. Agora, sem a proteção das gotas de sangue, a jovem princesa estava em suas mãos, sem poder se defender (GRIMM, 1995: 4)

\section{O agressor engana a vítima}

O engano é revelado durante a viagem, na qual a aia que acompanhava a princesa, mostra-se má, ao declarar que não é sua serva: "Por favor, apeie, o meu copo de ouro e traga-me um copo d’água. / - Se tem sede - respondeu a aia com arrogância - apeie você mesma, abaixe-se e beba. Não sou sua criada!” (GRIMM, 1995: 2-3).

\section{O agressor faz um mal prejudicando o herói}

A perda do lenço enfraqueceu a princesa, e a aia tirou partido disso. Forçou-a a trocar os cavalos e a roupa, fazendo-a jurar que não contaria uma palavra sobre o acontecido. Assim, a princesa passou a ter o aspecto de criada, e esta de princesa.

- Quem vai montar no Falante sou eu! Você fica com o meu cavalo!

Obrigou-a também a tirar as vestes reais e vestir as dela, roupas simples, bastante usadas, e ainda, jurar sob ameaça de morte que não diria a ninguém uma palavra sobre o acontecimento, quando chegassem à corte real (GRIMM, 1995: 5). 


\section{Chegada incógnita}

A chegada incógnita é representada pela chegada da princesa, como se fosse uma criada, à casa do rei, onde estava o príncipe. O rei reparou nos gestos finos da moça. Tal observação é um indício para o futuro reconhecimento. A verdadeira princesa passa a trabalhar como guardadora de gansos, e a aia assume o seu lugar:

O príncipe veio ao encontro delas e ajudou a aia a descer do cavalo, julgando-a sua noiva. Depois acompanhou-a pela escadaria acima e entraram no palácio. A pobre princesa ficou no pátio, como convinha a uma criada. Contudo, o velho rei viu-a da janela e, reparando nos seus modos finos e na sua beleza, foi aos aposentos e perguntou à falsa noiva quem era aquela moça que viera com ela e ficara no pátio.

- É apenas uma criada que veio para servir-me durante a viagem - respondeu ela. - Dê-lhe um serviço qualquer, pois não quero que fique ociosa.[...] $\mathrm{E}$ a jovem passou a trabalhar com o guardador de gansos, que se chamava Conrado (GRIMM, 1995: 5-7).

\section{O objeto mágico é posto à disposição do herói}

O objeto mágico é constituído pela figura do cavalo Falante, que teve a cabeça cortada a pedido da impostora, porque temia ser denunciada. Ao saber disso, a princesa pediu ao magarefe que pendurasse a cabeça do cavalo no portão, localizado na saída da cidade, por onde passava todos os dias. Na manhã seguinte, quando a princesa e o guardador de gansos atravessaram o portão, a cabeça mágica falou:

Ai de ti, princesa minha, pastora que és agora, se tua mãe soubesse disso, morreria sem demora! (GRIMM, 1995: 14)

\section{A malfeitoria inicial é reparada}

A malfeitoria é reparada quando o rei toma conhecimento, por intermédio de Conrado, o guardador de gansos, das palavras proferidas pela cabeça do cavalo. O rei arguiu a princesa, e ela disse que nada poderia revelar, pois estava presa a um juramento. Então, o rei aconselhou-a a desabafar suas mágoas dentro da lareira; e assim ela o fez.

O rei, que, do lado de fora, com o ouvido colado à chaminé da lareira, escutou tudo, tornou a entrar, pediu à moça que saísse da lareira e ordenou às camareiras que lhe vestissem suas roupas reais. (GRIMM, 1995: 13)

\section{O herói é reconhecido}

O reconhecimento do herói dá-se quando o rei chamou o filho e apresentou-lhe sua verdadeira noiva, contando-lhe toda a verdade a seu respeito. O príncipe fica muito feliz: "Não é preciso dizer o quanto o rapaz se alegrou, pois, ver e amar a princesa foi coisa de um instante e, na realidade, a falsa noiva nunca lhe agradou” (GRIMM, 1995: 13). 
10. O herói recebe nova aparência

O herói recebe uma nova aparência em decorrência do reconhecimento de sua verdadeira identidade. A nova aparência da princesa ocorre pela substituição de suas vestes de criada por roupas reais. A impostora não a reconhece na festa oferecida pelo rei: “O príncipe ocupou o lugar de honra, tendo de um lado a princesa, de outro a aia. Esta não sabia que havia sido desmascarada e não reconheceu a princesa em sua deslumbrante veste real” (GRIMM, 1995: 14).

\section{O agressor é desmascarado}

A agressora é desmascarada na festa. No final da refeição, o velho rei perguntou à falsa princesa qual seria o castigo para uma pessoa que tivesse agido de um certo modo, descrevendo o dela. Ela respondeu que seria a pena de morte. O rei, então, a desmascarou:

E perguntou o que ela achava de uma pessoa que traiu seus amos e assim e tal, contou toda a história da princesa, como se tivesse acontecido com outra pessoa, em outros tempos, num outro lugar. E ela respondeu sem titubear:

- Essa pessoa é uma criminosa e merece ser condenada.

- E se você fosse o juiz, que pena lhe daria? - perguntou o rei.

- Pena de morte, é claro! Eu a condenaria a morrer na forca.

Então o rei levantou-se e, perdendo o seu ar jovial, disse com severidade:

Essa pessoa é você (GRIMM, 1995: 15-6).

\section{O agressor é punido}

A aia foi punida. O rei decretou-lhe a pena determinada por ela própria: "Você mesma foi o juiz, e a pena que escolheu ser-lhe-á aplicada” (GRIMM, 1995: 16).

\section{O herói casa-se}

Após o desmascaramento e a punição da agressora, volta-se ao equilíbrio inicial da narrativa, com o desfecho feliz, próprio dos contos de fadas, representado pelo casamento: “e, semanas depois, realizou-se o casamento do filho do rei com a verdadeira noiva. Nunca houve uma festa tão linda, nem um casal tão feliz” (GRIMM, 1995: 16).

A análise, de acordo com o modelo estabelecido por Propp, proporcionou a localização de treze funções no conto. As funções encontradas foram: interdição, afastamento, transgressão, engano, malfeitoria, chegada incógnita, objeto mágico, reparação, reconhecimento, descoberta, transfiguração, punição e casamento.

\section{Considerações finais}

“A guardadora de gansos” configura-se como um conto maravilhoso por representar uma situação que transcende a realidade, apresentando os fatos da trama, através da magia e do encantamento. O lenço da mãe, com as três gotas de sangue, o cavalo Falante, o vento que atende os pedidos da princesa e a lareira que ouve sua confissão são objetos mágicos que influem no desenrolar da narrativa, possibilitando um desfecho feliz. 
O espaço também apresenta-se como um elemento maravilhoso, pois não há dificuldades para o deslocamento da princesa de um reino ao outro, quando vai ao encontro de seu noivo, a cavalo. Esse espaço não é definido, podendo ser qualquer lugar, o que confere universalidade ao conto. O tempo, por sua vez, remete a um passado longínquo e não cronológico. É um tempo distante do vivenciado pelo leitor.

O casamento simboliza a vitória do herói sobre a malfeitoria, representando também uma volta à estabilidade da situação inicial.

Com esse trabalho, esperamos contribuir com mais uma opção para a análise do conto maravilhoso para os professores de língua e literatura e, em especial, aos alunos do Curso de Letras.

\section{Referências}

GRIMM. A guardadora de Gansos. São Paulo: Ática, 1992.

GOTLIB, N B. Teoria do Conto. São Paulo: Ática, 1985.

MACHADO, I A. Literatura e redação. São Paulo: Scipione, 1994.

PROPP, V. Morphologie du conte. Paris: Editions du Seuil, 1970. 